\title{
A Further Test of the Impact of Online Gaming on Psychological Wellbeing and the Role of Play Motivations and Problematic Use
}

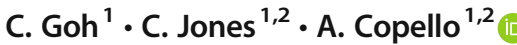

Published online: 5 August 2019

(C) The Author(s) 2019

\begin{abstract}
The impact of increased online gaming play time on psychological wellbeing was examined focusing on the Multiplayer Online Battle Arena (MOBA) game genre. This relationship was explored with respect to motivators for playing and resilience factors. A cross-sectional, online questionnaire design was employed with participants $(N=165)$ to examine the relationship between weekly average hours played and psychological wellbeing. Five previously reported motivators for playing were tested as mediating variables. In addition, exploratory analyses were conducted to determine the moderating effects of self-esteem and self-efficacy on 'escapist' gaming and psychological wellbeing. Results revealed a significant correlation with higher levels of play time associated with poorer psychological wellbeing. This relationship was partially mediated by 'escapist' motivation. Self-esteem was found to moderate the negative impact of 'escapist' gaming on psychological wellbeing. Research and the associated clinical implications are discussed.
\end{abstract}

Keywords Multiplayer Online Battle Arena (MOBA) · Online games · Problematic gaming · Motivators for playing $\cdot$ Escapism $\cdot$ Self-esteem $\cdot$ Self-efficacy

\section{Introduction}

The number of people using online platforms for gaming has increased exponentially during the last decade; a report by ComScore [6] suggested that almost 217 million people play games online annually. With the proliferation of online games, there has been increasing concern over the excessive use of gaming and the ramifications on psychological wellbeing. The most extensively researched online gaming genre in the recent literature involves Massively

A. Copello

a.g.copello@bham.ac.uk

1 School of Psychology, University of Birmingham, Edgbaston B15 2TT, UK

2 Birmingham and Solihull Mental Health Foundation Trust, Edgbaston, UK 
Multiplayer Online Role Playing Games (MMORPGs). Studies have demonstrated that low self-esteem, depressive symptoms, problematic gaming behaviour, and poorer general health result from the problematic use of MMORPGs (e.g. [35, 38, 46]). Kuss et al. [25] suggested that the immersive properties found in MMORPG gameplay, namely escapism (i.e. avoidance of real-life problems), role-playing (i.e. adopting an in-game persona), and character customisation (i.e. personalisation of character), are associated with more problematic outcomes. At present it is unclear whether the reported impact is specific to MMORPG's or a more general effect of problematic use of computer gaming.

The Multiplayer Online Battle Arena (MOBA) gaming genre has experienced a rapid rise in popularity over the past five years [37]. The shift from MMORPGs to MOBA games is evident through MOBA's greater active player population and international recognition as a competitive sport. Even though MOBA games share features with MMORPGs (such as multiplayer online interaction and single character control), MOBA games are distinct in terms of their game mechanisms and lack the role-playing element found in MMORPGs, with the MMORPG having a strong investment in character development and encouraging immersion during long periods of in game-play. In contrast, MOBA involves relatively short team matches (30-60 min) after which the players characters are reset.

It is not known if playing MOBA games, which are distinct from MMORPGs in terms of its game mechanics, are likewise associated with poorer psychological outcomes. It is therefore important to explore the association between playing online games and psychological wellbeing in the context of other gaming genres such as MOBAs, and whether other factors influence this relationship.

\section{Impact of Online Games}

Research in online MMORPG gaming tends to emphasise its negative impact on psychological wellbeing, with studies suggesting that MMORPG players are more vulnerable to negative psychological and physical outcomes [25, 35, 28, 30, 34]. Less attention has been given to the positive impact of online gaming on psychological wellbeing, such as helping players develop social skills, foster a social support network, enhance positive affect, and improve wellbeing $[10,19,29,51,53]$. It is imperative to further evaluate the relationship between online gaming and psychological wellbeing, as there may be important factors that can influence the direction and strength of this relationship.

\section{Motivations for Playing}

Demetrovics et al. [9] posit that behaviour is largely determined and influenced by motives. The investigation into motivational factors is not new and has been examined in the field of addiction studies. For example, motivations for drinking were found to account for $50 \%$ of the variance in adolescent alcohol use [26]. Accordingly, understanding the motives and needs underlying why individuals play online games may lead to greater insight into the relationship between excessive use and psychological wellbeing.

Kahn et al. [23] developed a scale examining players' motivations for playing games in the context of MOBA and MMORPG gaming genres. The authors argued that while other scales exist (e.g. [54]); they are limited in terms of their focus on specific gaming genres or lack of behavioural validation. Kahn et al. [23] conducted an exploratory factor analysis for items taken from past scales assessing the motivations for playing various video games $[45,54]$. The 
analysis revealed six factors reflecting six distinct types of players: 'socialisers' (i.e. playing to socialise with others); 'completionists' (i.e. playing to complete every aspect of the game); 'competitors' (i.e. playing to win); 'escapists' (i.e. playing to escape from real life); 'story driven' (i.e. playing because of the story development); and 'smarty-pants' (i.e. playing to enhance their intelligence). The scale was thereafter validated on both the MOBA and MMORPG gaming genres.

'Escapist' players are defined as individuals who use gaming to escape from real life [23, 27]. Several studies highlighted that the motivation for escapism and immersive gaming are associated with negative psychological and social outcomes (e.g. [4, 24, 48]). Griffiths [20] identified that adults who engaged in gaming to escape from real-life problems experienced negative consequences on wellbeing compared to adults who played to socialise. Similarly, Stetina et al. [48] discovered that while 'escapist' gaming may act as a coping strategy for dealing with real-life difficulties, this was associated with more problematic outcomes. More recently, Kirby et al. [24] identified the role of players' motivation as mediating the relationship between the amount of time spent playing MMORPGs and psychological wellbeing. Yee's [54] three motivators for playing MMORPGs (Achievement, Social Interaction, and Immersion) were tested as mediators between play time and psychological wellbeing. The study found that increased play is associated with poorer psychological wellbeing, specifically where there is greater player motivation for immersion and escapism, which points towards a negative association between using games to escape from real-life problems and poor mental health.

Nonetheless, the negative outcomes associated with 'escapist' gaming may be mitigated by resilience factors. Literature on resilience factors has demonstrated how self-esteem can act as a defence mechanism by protecting individuals from experiences that are harmful $[36,47,50]$. Thoits [50] postulates that self-esteem protects individuals from threats to the self while attempts to resolve the problem are made. Similarly, self-efficacy, which is having the selfbelief that one can overcome challenging environmental demands, has been demonstrated to promote effective coping strategies when dealing with stressors in life [1, 22]. Conversely, individuals with low self-esteem and/or self-efficacy may be more prone to the negative effects of 'escapist' gaming. Accordingly, it would be important to examine the potential of such resilience factors in moderating the impact of 'escapist' gaming.

\section{Study Aims}

The aim of the present study was therefore to examine the relationship between the amount of time spent playing DOTA 2 (a popular MOBA) and psychological wellbeing. Five ${ }^{1}$ out of six Kahn et al. [23] motivations for play were tested as mediating variables. Overall, it was hypothesised that:

1) Greater time spent playing DOTA 2 would be associated with poorer psychological wellbeing.

2) In line with the findings from Kirby et al. [24], Khan et al.'s (2015) 'escapist' motivator for playing would mediate the association between play time and psychological wellbeing.

\footnotetext{
${ }^{1}$ The 'story-driven' sub-scale did not appear to be relevant to DOTA 2 players as the game is not story driven.
} 
3) Using Khan et al. (2015) motivators for playing, the mediating effect of 'socialisers', 'completionists', 'competitors', and 'smarty-pants' will be examined.

Additionally, the potential moderating effects of self-esteem and self-efficacy between motivation for play and psychological wellbeing was explored.

\section{Method}

\section{Participants}

Participants were people who perceived themselves to be regular DOTA 2 players and were recruited by online advertisements on gaming websites. There was no restriction placed upon play time across the sample of players. The inclusion criteria were:

1) Adults, aged eighteen and over, who perceive themselves as regular DOTA 2 players;

2) Fluency in the English language, in order to be able to accurately and appropriately fill in the questionnaires;

3) A score of less than seven on the short version of the Social Desirability Scale.

One hundred and sixty-five participants ${ }^{2}$ took part in the study (155 males and ten females). To control for response bias, participants who scored seven or above on the Social Desirability Scale were excluded from further analyses $(n=16,9.7 \%)$. Analyses were conducted for 149 participants (142 males and 7 females).

\section{Measures}

Play time was assessed via self-report, in terms of gameplay days per week, hours per day and hours per week. The distribution for play time was positively skewed with the median play time at $18 \mathrm{~h}$ per week.

\section{Psychological Wellbeing}

Goldberg and Hillier's [15] General Health Questionnaire (GHQ-28) was used as measure of Psychological Wellbeing. The questionnaire contains four subscales; Somatic Problems, Anxiety and Insomnia, Social Functioning and Depression. Each item is scored on a fourpoint Likert scale (from zero $=$ no difficulties to three $=$ much greater difficulties than usual). A higher score is indicative of poorer psychological wellbeing. The Cronbach's Alpha Score for the scale is 0.9 [11].

\section{Motivations for Play}

Kahn et al.'s [23] Trojan Player Typology scale is a 15-item questionnaire used to identify players' motivation for playing DOTA 2. Play motivators include 'socialisers', 'completionists',

\footnotetext{
${ }^{2}$ Based on the calculations of Fritz and MacKinnon [13], a sample size of 71 participants allows for the identification of medium sized mediation effects (i.e. with path coefficients of at least .39), with a power of 0.80 .
} 
'competitors', 'escapists', 'story driven', and 'smarty-pants'. Participants were required to record their extent of agreement with statements relating to various aspects of gameplay. Each item is scored on a five-point Likert scale, where zero implied 'strongly disagree' and five implied 'strongly agree'. As mentioned, the 'story-driven' motivation was removed following pilot testing due to its lack of relevance to DOTA 2 players. Khan et al. (2015) reported that the Cronbach's Alpha reliability coefficients for each motivation are 'Socialisers' (.69), 'Completionists' (.67), 'Competitors' (.75), 'Escapists' (.70), and 'Smarty-pants' (.79) respectively.

\section{Self-Esteem}

Rosenberg's [42] Self-Esteem Scale was used as a measure of self-esteem. The scale is a tenitem questionnaire in which respondents indicate on a four-point Likert scale (from one = strongly disagree to four = strongly agree) the extent of their agreement of the statements. Higher scores indicate higher self-esteem. Rosenberg [42] reported that the scale had good internal consistency (.77). A varied selection of independent studies using such samples asparents, men over 60 , high school students, and civil servants, - showed alpha coefficients ranging from 0.72 to 0.87 .

\section{Self-Efficacy}

Schwarzer and Jerusalem's [44] Generalised Self-Efficacy Scale was used. The self-efficacy scale is a ten-item questionnaire, in which respondents indicate on a four-point Likert scale (from one $=$ not true at all to four $=$ exactly true) the extent of agreement with the statements. A higher score is indicative of higher self-efficacy. The scale has good internal consistency $(.82$ to .93) for the samples studied.

\section{Social Desirability}

The short version of the Social Desirability Scale (SDS; [49]) was used. The scale includes ten true/false statements designed to reveal social desirability in the respondent. Higher scores indicate a greater tendency to present oneself in a positive manner. Fischer and Fick [12] reported that the short version of the SDS has good internal consistency (.88) and is highly correlated with the original scale (.96) developed by Crowne and Marlowe [7].

\section{Procedure}

The research study was advertised to players of DOTA 2, both via game forums (internet webpages set up for groups of players to discuss issues) and social media sites (e.g. DOTA 2 Facebook pages). The survey was undertaken online using the Limesurvey survey programme [43]. Demographic questions were presented first, followed by the General Health Questionnaire, the Motivations for Play Questionnaire, the Rosenberg Self-Esteem Scale, the Generalised Self-Efficacy Scale, and the Social Desirability Scale.

\section{Data Analysis}

The distribution for play time was positively skewed with the median play time at $18 \mathrm{~h}$ per week. Accordingly, nonparametric statistical procedures have been used were possible. 
Bootstrap confidence intervals are robust to the violation of parametric assumptions [33]. Therefore, bootstrap CIs were used for inferential tests. Unless otherwise stated, bootstrap results are based on 5000 bootstrap samples and the bias corrected and accelerated bootstrap confidence intervals are provided.

A zero-order correlation was used to determine the relationship between the independent variable (average number of hours spent playing per week) and the dependent variable (psychological wellbeing). To determine the potential mediating effect of motivations for playing the Preacher and Hayes' [39, 40] model of mediation was used. In addition to calculating multiple mediator values simultaneously, the model handles the violation of parametric inference assumptions by reporting bias corrected and accelerated bootstrap confidence intervals. Preacher and Hayes $[39,40]$ have argued that this method is more robust than non-parametric statistical procedures and has a higher statistical power than the standard Sobel Test of mediation.

\section{Results}

\section{Sample Characteristics}

The participants' demographic information is presented in Table 1. Participants originated from 30 countries although the largest number was from the UK $(28 \%)$.

The pattern of DOTA 2 play for the sample is summarised in Table 2. The majority of participants indicated that they had been playing the game for more than four years $(34.2 \%)$. Eighty-four percent of participants reported having played the game for two years or more. The mean level of game experience recorded by participants was level 100.28 (SD=56.9), which indicates that they had invested a substantial amount of time in playing DOTA 2.

The total score of the GHQ represents overall wellbeing and a higher score is indicative of poorer psychological wellbeing. The mean GHQ score for the sample was $21.80(\mathrm{SD}=12.90)$ and scores ranged from 3 to 56 . The presence of mental health difficulties was determined according to the procedure described by Goldberg et al. [16]. Using this method, the Likert scores (0-1-2-3) were recoded (0-0-1-1) and a total score exceeding the cut-off of six was considered indicative of 'caseness'. In the sample, $27.5 \%(n=41)$ of the participants exceeded the cut-off for caseness.

Table 1 Summary of sample demographic variables

\begin{tabular}{lll}
\hline & Categories & N $(\%)$ \\
\hline \multirow{2}{*}{ Gender } & Male & $142(95.3)$ \\
Relationship Status & Female & $7(4.7)$ \\
& Single & $114(76.5)$ \\
& Married & $5(3.4)$ \\
& Cohabiting & $21(14.1)$ \\
Employment & Divorced & $1(0.7)$ \\
& Other & $8(5.4)$ \\
& Full time employment & $44(30)$ \\
& Part time employment & $19(12.8)$ \\
& Unemployed & $8(5.4)$ \\
& Student & $77(51.7)$ \\
\hline
\end{tabular}


Table 2 Pattern of play

\begin{tabular}{llll}
\hline & & Mean (SD) & Range \\
\hline Age & & $23.2(4.67)$ & $18-44$ \\
Play Pattern & Hours per week & $22.74(16.19)$ & $1-70$ \\
& Years playing & $5.22(1.69)$ & $<1->4$ \\
& Days per week & $3.99(2.26)$ & $1-7$ \\
Game experience & Hours per day & $100.28(56.89)$ & $1-10$ \\
\hline
\end{tabular}

No significant correlations were found between age and the total GHQ score $(\mathrm{r}=-0.051$, 95\% CI [ -0.19 to 0.09$]$ ), the Somatic Problems subscale ( $\mathrm{r}=-0.02,95 \%$ CI [ -0.15 to 0.12$]$ ), the Anxiety and Insomnia subscale $(\mathrm{r}=-0.05,95 \% \mathrm{CI}[-0.20$ to 0.11$]))$, the Social Functioning subscale $(\mathrm{r}=-0.04,95 \% \mathrm{CI}[-0.17$ to 0.10$])$, and the Depression subscale $(\mathrm{r}=-0.06,95 \%$ CI [ -0.19 to 0.09$])$.

Rosenberg's Self-Esteem Scale [42] was used to measure global self-worth. A high score is indicative of higher self-esteem. The mean score was $27.97(\mathrm{SD}=5.10)$ and scores ranged from 17 to 40 . There was no significant correlation found between self-esteem and age $(\mathrm{r}=$ $0.06,95 \%$ CI [ -0.10 to 0.20$])$.

The General Self-Efficacy Scale (1995) identifies individuals' belief in terms of their ability to respond to difficult situations or setbacks. A higher score represents higher self-efficacy. A mean score of $29.75(\mathrm{SD}=5.46)$ was obtained and the scores ranged from sixteen to 40. Age was not found to be significantly correlated with self-efficacy $(r=0.15,95 \%$ CI $[-0.06$ to 0.31]) (Table 3).

\section{The Association between Play Time and Psychological Wellbeing}

The impact of play time on psychological wellbeing was evaluated in terms of the relationship between the average number of hours played per week and the total GHQ score. A significant positive correlation was obtained between play time and GHQ scores $(r=0.43,95 \%$ CI [0.28 to 0.57$]$ ). Results suggest that as the amount of play time per week increased, the greater the GHQ scores were (i.e. poorer psychological wellbeing), accounting for approximately $18 \%$ of the variance.

Significant positive correlations were also found for each of the GHQ subscale scores; Somatic Problems ( $r=0.40,95 \%$ CI [0.22 to 0.55]), Anxiety and Insomnia ( $r=0.36,95 \%$ CI [0.20 to 0.50$]$ ), Social Functioning ( $\mathrm{r}=0.32,95 \% \mathrm{CI}$ [0.17 to 0.47]), and Depression $(\mathrm{r}=0.37$, $95 \%$ CI [0.22 to 0.52]). Altogether, the results indicated that a greater number of hours spent playing DOTA 2 is associated with poorer levels of overall psychological wellbeing.

\section{Mediation Analysis}

Five mediated paths were included in the Preacher and Hayes' [39, 40] mediation model ('socialisers', 'completionists', 'competitors', 'escapists', and 'smarty-pants'). The significance of the mediated pathways was evaluated via bootstrap bias corrected and accelerated confidence intervals of the path coefficients of the model.

In the unmediated null model, the effect of play time on psychological wellbeing was $\beta=$ $0.35,95 \%$ CI [ 0.23 to 0.46$]$. This was reduced to $\beta=0.22,95 \%$ CI [ 0.12 to 0.32$]$ when the 
mediating effect of the motivators were included. Therefore, the sum of the indirect effects within the mediation model was $\beta=0.12,95 \% \mathrm{CI}[0.03$ to 0.22$]$.

Figure 1 illustrates the individual path coefficients for each motivator for playing and the associated significance tests. In terms of the overall mediation effects, the 'socialiser' motivator was not found to be significant ( $\beta=0.003,95 \%$ CI [ -0.01 to 0.03$])$. Similarly, the paths mediated by the 'completionist' motivator $(\beta=0.01,95 \%$ CI $[-0.01$ to 0.04$])$, 'competitor' motivator $(\beta=-0.003,95 \%$ CI $[-0.03$ to 0.02$])$, and 'smart-pants' motivator ( $\beta=-0.003$, $95 \%$ CI [ -0.02 to 0.01$]$ ) did not show a significant overall effect. Consistent with the findings of Kirby et al. [24], only the path mediated by the 'escapist' motivation yielded a significant overall effect $(\beta=0.12,95 \%$ CI $[0.05$ to 0.20$])$. Accordingly, a partial mediation effect was observed (Fig. 1).

These results indicated that the 'escapist' motivation significantly mediated the relationship between play time and psychological wellbeing. The positive beta value indicates that the greater number of hours spent playing, alongside increased escapism, is related to poorer psychological wellbeing. However, the association between play time and psychological wellbeing was not fully mediated by the 'escapist' motivator, indicating that there may be other variables not accounted for by the model that mediate this relationship.

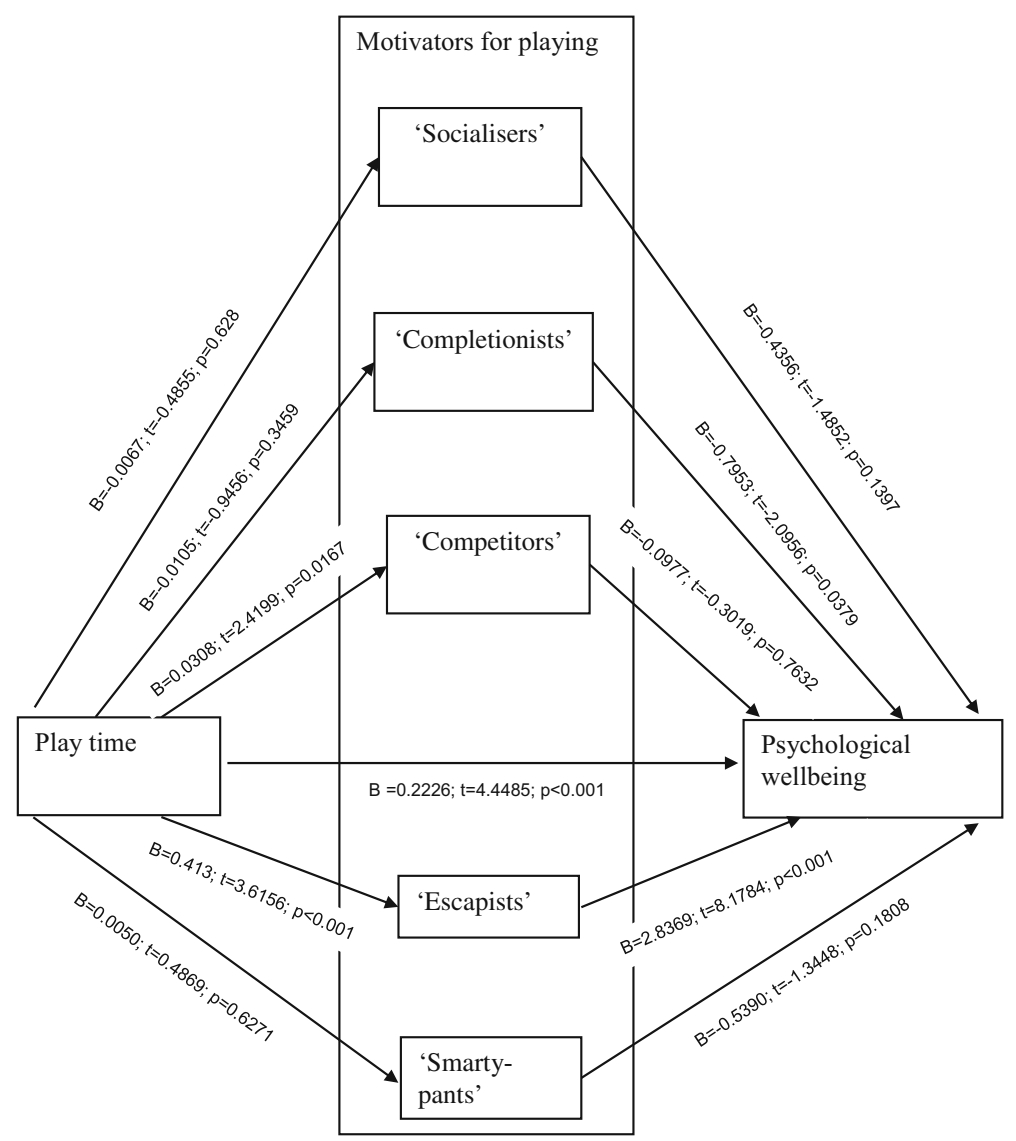

Fig. 1 Mediation model with statistical effects of pathways 


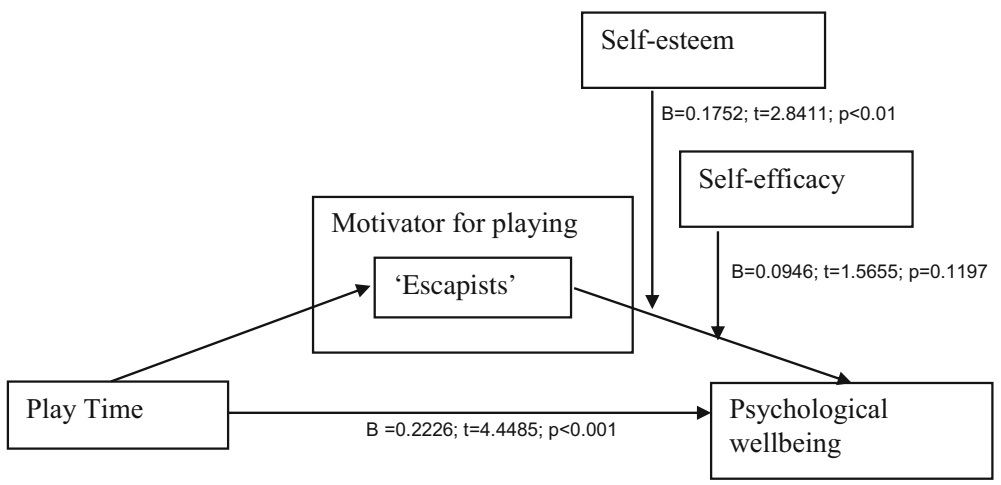

Fig. 2 Moderator model with statistical effects of pathways

An exploratory analysis was thereafter conducted to determine whether resilience factors such as self-esteem and self-efficacy moderated the negative impact of the 'escapist' motivator for playing on psychological wellbeing (Fig. 2). Preacher and Hayes' [39, 40] mediator moderator analysis procedure was used to explore the potential interaction effect between self-esteem (and self-efficacy) and escapism on psychological wellbeing. In order to aid the interpretation of the interaction effect, the self-esteem was reverse coded so that a positive score would indicate low levels of self-esteem. The product of self-esteem and the 'escapist' motivation was then calculated. The same procedure was replicated for the construct of selfefficacy and its interaction with escapism.

The results yielded a positive interaction effect between escapism and self-esteem ( $\beta=$ $0.18,95 \%$ CI [ 0.05 to 0.30$]$ ). It can therefore be concluded that the relationship between the 'escapist' motivator for play and psychological wellbeing is moderated by the level of selfesteem. The positive beta value indicates that individuals with low self-esteem who play the game to escape have poorer psychological wellbeing overall.

The mediator moderator analysis however did not reveal a significant interaction between escapism and self-efficacy ( $\beta=0.09,95 \%$ CI $[-0.02$ to 0.21$])$. The results suggest that the relationship between the 'escapist' motivator for play and psychological wellbeing is not moderated by self-efficacy.

\section{Discussion}

The present study aimed to examine the relationship between time spent playing Multiplayer Online Battle Arena (MOBA) games and psychological wellbeing, with motivators for playing as potential mediating factors. The study's results suggest that increasing play time is associated with poorer psychological wellbeing, and that this relationship is mediated by the 'escapist' motivation. Further, the study found that low levels of self-esteem, alongside increasing escapism, were associated with poorer psychological wellbeing.

From the sample, $27.5 \%$ of participants met criteria for a diagnosable mental health problem. This is a slightly elevated statistic compared to the prevalence rates of mental health difficulties in the UK population, estimated to be around $17 \%$ of the population [32]. The higher proportion of online gamers suffering from mental health difficulties is likewise reflected in other studies examining mental health amongst online gamers (e.g. [24, 52]). 
A significant positive correlation was found between the hours spent playing DOTA 2 per week and GHQ scores; a higher number of hours spent playing the game was found to be associated with poorer psychological wellbeing. A moderate effect size and $18 \%$ of the variance in psychological wellbeing can be explained by the amount of time spent playing the game. Similarly, the association between GHQ subscale scores and psychological wellbeing explained $10 \%$ to $16 \%$ of the variance. The results suggest that there is an increased likelihood of mental health difficulties amongst individuals who invest a significant amount of time playing DOTA 2. While the moderate effect size provides some evidence for mental health risks associated with increased play time, it cannot fully explain why some individuals who invest as much time into the game do not experience negative outcomes.

Kahn et al. [23] motivators for playing were considered in the context of this relationship. Specifically, five motivators were tested as mediators; 'socialisers', 'completionists', 'competitors', 'escapists' and 'smart-pants'. Previous research has found that individuals who play MMORPGs as a means to escape from real-life difficulties are at most risk of negative outcomes $[3,4,20,24,28]$. The primary aim of the present study was to see if this association could be replicated in the MOBA gaming genre. The findings from the present study demonstrated that playing DOTA 2 as a means for escapism mediated the relationship between play time and psychological wellbeing. The remaining four motivators for play did not mediate the relationship between play time and psychological wellbeing.

The results from the present study and from Kirby et al.'s [24] study suggest that 'escapist' gaming may be used as an avoidant coping strategy for real-life difficulties [48]. The link between avoidant coping strategies and negative outcomes has been studied in the literature; avoidant coping strategies have been shown to have an association with negative consequences, such as depression or increased stress $[2,21]$. Similarly, the literature on problem gambling has established a link between escapism and negative outcomes [8, 41]. Accordingly, when an individual uses gaming as a coping mechanism to escape from real-life problems, the association between longer play time and poorer mental health is strengthened.

Unlike the expansive virtual worlds in MMORPGs and the long-term investment in a single character, MOBA games only offer a single virtual arena and character statistics reset after a victory or a loss. The research in MMORPGs appears to suggest that the escapist properties are more pronounced given the opportunity for immersion in a virtual realm and the experience of a different life through a game character [54]. However, the current study's findings challenge this conclusion; these findings suggest that playing MOBA games (that do not offer the kind of

Table 3 Summary of test variables

\begin{tabular}{lll}
\hline & & Mean (SD) \\
\hline GHQ-28 & & $21.80(12.9)$ \\
& Total & $4.85(3.26)$ \\
& Somatic & $5.44(4.11)$ \\
& Anxiety \& Insomnia & $7.26(3.06)$ \\
Self-Esteem & Social functioning & $4.23(4.93)$ \\
Self-Efficacy & Depression & $27.97(5.10)$ \\
Play Motivation & Total & $29.75(5.46)$ \\
& Total & $10.56(2.7)$ \\
& Socialisers & $11.75(2.19)$ \\
& Completionists & $10.48(2.55)$ \\
& Competitors & $6.02(2.34)$ \\
& Escapist & $6.17(2.01)$ \\
\hline
\end{tabular}


expansive virtual environment or character immersion akin to that of MMORPGs), is still associated with poorer mental health when an individual plays the game to escape from real life. The present study identified that the relationship between play time and psychological wellbeing is not fully mediated by the 'escapist' motivation. This suggests that there are other variables contributing to this relationship that are not accounted for by the model. Kirby et al.'s study [24] reported that there was no direct effect of play time on psychological wellbeing when the mediated variables were accounted for (i.e. character customisation, escapism and problematic use). There may be other variables not accounted for in the model used in the present study that likewise mediate the relationship between play time and psychological wellbeing, which could be explored in future research.

In terms of the role of resilience factors, self-esteem was found to be a moderator for escapism and mental health. In other words, the negative effects of using games to escape from real-life problems are influenced by an individual's self-esteem. Martyn-Nemeth et al. [31] reported that low self-esteem was associated with avoidance coping and depressive mood. Similarly, Chapman and Mullis [5] reported that adolescents with lower self-esteem utilised more avoidant coping strategies compared to adolescents with higher self-esteem. It is possible that individuals who already suffer from low self-esteem play online games as a way to avoid real-life threats to themselves, and this form of coping, via avoidance, leads to poorer mental health. There may however be a host of alternative explanations regarding the way selfesteem influences the relationship between escapism and psychological wellbeing. Self-efficacy was not found to moderate the relationship between escapism and psychological wellbeing.

While the present study is similar to other studies focusing on the MMORPG genre in terms of a sample comprising of predominantly male online gamers (e.g. [17, 24, 54]), the gender distribution was extremely skewed towards males in the present study (20:1). The majority of the sample was from the UK and it is not known whether results would be generalisable to online gamers in different geographic locations, as motivations for play may vary based on cultural factors. The present study excluded participants under the age of eighteen years. However, the impact of games on age may vary for children and adolescents (e.g. [18]). While a correlational design was selected for the present study, a longitudinal study design is more appropriate for conclusions on causality to be drawn. A previous study that employed a longitudinal design found that the existence of greater impulsivity, in addition to a larger amount of time spent playing, together with low social competence, were risk factors for pathological gaming, contributing in turn to poorer mental health outcomes [14].

\section{Summary of Conclusions}

The present study aimed to shed some light on the relationship between play time in MOBA games and psychological wellbeing. While some evidence exists showing that increased play time is associated with poorer psychological wellbeing, the 'escapist' motivator for playing was found to mediate this relationship. Increased MOBA gameplay was associated with poorer psychological wellbeing, specifically where there is greater motivation for escapism. The association between 'escapist' gaming and poor psychological wellbeing was strengthened for individuals with low self-esteem. 


\section{Compliance with Ethical Standards}

Ethical Approval The full study including all procedures performed with participants were reviewed and approved by the University of Birmingham, UK; Science, Technology, Engineering and Mathematical Ethics Review Committee: Ref: ERN_15-1624 in accordance with the ethical standards of the University Code of Practice for Research.

Informed Consent Informed consent was obtained from all individual participants included in the study.

Conflict of Interest Dr. Cian Goh declares that he has no conflict of interest. Dr. Chris Jones declares that he has no conflict of interest. Professor Alex Copello declares that he has no conflict of interest.

Open Access This article is distributed under the terms of the Creative Commons Attribution 4.0 International License (http://creativecommons.org/licenses/by/4.0/), which permits unrestricted use, distribution, and reproduction in any medium, provided you give appropriate credit to the original author(s) and the source, provide a link to the Creative Commons license, and indicate if changes were made.

\section{References}

1. Bandura A. Self-efficacy mechanism in human agency. Am Psychol. 1982;37(2):122-47.

2. Blalock JA, Joiner TE. Interaction of cognitive avoidance coping and stress in predicting depression/anxiety. Cogn Ther Res. 2000;24(1):47-65.

3. Brockmyer J, Fox C, Curtiss K, McBroom E, Burkhart K, Pidruzny J. The development of the game engagement questionnaire: a measure of engagement in video game-playing. J Exp Soc Psychol. 2009;45: 624-34.

4. Caplan S, Williams D, Yee N. Problematic internet use and psychosocial wellbeing among MMO players. Comput Hum Behav. 2009;25:1312-9.

5. Chapman PL, Mullis RL. Adolescent coping strategies and self-esteem. Child Study J. 1999;29(1):69-9.

6. ComScore (2007). Worldwide online gaming community reaches 217 million people. Retrieved from http://www.comscore.com/Press_Events/Press_Releases/2007/07/Worldwide_Online_Gaming_Growsu.

7. Crowne DP, Marlowe D. A new scale of social desirability independent of psychopathology. J Consult Psychol. 1960;24(4):349-54.

8. De Castro V, Fong T, Rosenthal RJ \& Tavares H. (2007) A comparison of craving and emotional states between pathological gamblers and alcoholics. Addictive Behaviors, 32(8), 1555-1564.

9. Demetrovics Z, Urbán R, Nagygyörgy K, Farkas J, Zilahy D, Mervó B, et al. Why do you play? The development of the motives for online gaming questionnaire (MOGQ). Behav Res Methods. 2011;43(3): 814-25.

10. Ducheneaut, N., Yee, N., Nickell, E., \& Moore, R. J. (2006). Alone together?: exploring the social dynamics of massively multiplayer online games. In Proceedings of the SIGCHI conference on Human Factors in computing systems, 407-416.

11. Failde I, Ramos I, Fernandez-Palacin F. Comparison between the GHQ-28 and SF-36 (MH 1-5) for the assessment of the mental health in patients with ischaemic heart disease. Eur J Epidemiol. 2000;16(4):3116.

12. Fischer DG, Fick C. Measuring social desirability: short forms of the Marlowe-Crowne social desirability scale. Educ Psychol Meas. 1993;53(2):417-24.

13. Fritz MS, MacKinnon DP. Required sample size to detect the mediated effect. Psychol Sci. 2007;18(3):2339.

14. Gentile, D., Choo, H., Liau, A., Sim, T.,Li, D., Fung, D. \& Khoo, A. (2011) Pathological video game use among youths: a two year longitudinal study. Paediatrics, 127, 319-329.

15. Goldberg DP, Hillier VF. A scaled version of the general health questionnaire. Psychol Med. 1979;9(01): $139-45$.

16. Goldberg, D., Williams, P., \& Williams, P. (1988). A user's guide to the general health questionnaire. NferNelson.

17. Griffiths MD, Davies MN, Chappell D. Breaking the stereotype: the case of online gaming. Cyberpsychol Behav. 2003;6(1):81-91. 
18. Griffiths MD, Davies MN, Chappell D. Online computer gaming: a comparison of adolescent and adult gamers. J Adolesc. 2004;27(1):87-96.

19. Griffiths MD. The role of context in online gaming excess and addiction: some case study evidence. Int $\mathrm{J}$ Ment Heal Addict. 2009;8:119-25.

20. Griffiths M. The role of context in online gaming excess and addiction: some case study evidence. International Journal of Mental Health Addiction. 2010;8:119-25.

21. Holahan C, Moos R, Holahan C, Brennan P, Schutte K. Stress generation, avoidance coping, and depressive symptoms: a 10-year model. J Consult Clin Psychol. 2005;73:658-66.

22. Jerusalem M, Schwarzer R. Self-efficacy as a resource factor in stress appraisal processes. In: Schwarzer R, editor. Self-efficacy: thought control of action. New York, NY: Routledge; 1992. p. 195-213.

23. Kahn AS, Shen C, Lu L, Ratan RA, Coary S, Hou J, et al. The Trojan player typology: a cross-genre, crosscultural, behaviorally validated scale of video game play motivations. Comput Hum Behav. 2015;49:354 61.

24. Kirby A, Jones C, Copello A. The impact of massively multiplayer online role playing games (MMORPGs) on psychological wellbeing and the role of play motivations and problematic use. Int J Ment Heal Addict. 2014;12(1):36-51.

25. Kuss DJ, Louws J, Wiers RW. Online gaming addiction? Motives predict addictive play behavior in massively multiplayer online role-playing games. Cyberpsychol Behav Soc Netw. 2012;15(9):480-5.

26. Kuntsche E, Knibbe R, Gmel G, Engels R. Why do young people drink? A review of drinking motives. Clin Psychol Rev. 2005;25(7):841-61.

27. Li D, Liau A, Koo A. Examining the influence of actual-ideal self-discrepancies, depression, and escapism, on pathological gaming among massively multiplayer online adolescent gamers. Cyberpsychol Behav Soc Netw. 2011;14(9):480-5.

28. Liu M, Peng W. Cognitive and psychological predictors of the negative outcomes associated with playing MMOGs (massively multiplayer online games). Comput Hum Behav. 2009;25(6):1306-11.

29. Longman H, O'Connor E, Obst P. The effect of social support derived from world of Warcraft on negative psychological symptoms. Cyberpsychol Behav. 2009;12:563-6.

30. Lo SK, Wang CC, Fang W. Physical interpersonal relationships and social anxiety among online game players. Cyberpsychol Behav. 2005;8(1):15-20.

31. Martyn-Nemeth P, Penckofer S, Gulanick M, Velsor-Friedrich B, Bryant FB. The relationships among selfesteem, stress, coping, eating behavior, and depressive mood in adolescents. Res Nurs Health. 2009;32(1): 96-109.

32. Mind (2007). Retrieved from http://www.mind.org.uk/help/research_and_policy/statistics_1_how_ common is mental distress.

33. Moore, D. S., \& McCabe, G. P. (2005). Bootstrap methods and permutation tests. In Introduction to the Practice of Statistics. WH Freeman \& Co.

34. Morgan C, Cotten SR. The relationship between internet activities and depressive symptoms in a sample of college freshmen. Cyberpsychol Behav. 2003;6(2):133-42.

35. Ng B \& Wienner-Hastings P. (2005) Addiction to the internet and online gaming. Cyberpsychology and Behavior, 8, 110-113.

36. Pearlin LI, Schooler C. The structure of coping. J Health Soc Behav. 1978;19:2-21.

37. Pereira, C. (2014). League of Legends now has 27 million players daily. IGN entertainment. Retrieved from http://www.ign.com/articles/ 2014/01/29/league-of-legends-now-has-27-million-players-daily.

38. Porter G, Starcevic V, Berle D, Fenech P. Recognizing problem video game use. Aust N Z J Psychiatry. 2010;44(2):120-8.

39. Preacher KJ, Hayes AF. SPSS and SAS procedures for estimating indirect effects in simple mediation models. Behav Res Methods Instrum Comput. 2004;36(4):717-31.

40. Preacher KJ, Hayes AF. Asymptotic and resampling strategies for assessing and comparing indirect effects in multiple mediator models. Behav Res Methods. 2008;40(3):879-91.

41. Reid R, Li D, Lopez J, Collard M, Parhami I, Karim R, et al. Exploring facets of personality and escapism in pathological gamblers. J Soc Work Pract Addict. 2011;11(1):60-74.

42. Rosenberg, M. (1965). Rosenberg self-esteem scale (RSE). Acceptance and commitment therapy. Measures package, 61, 52 .

43. Schmitz, C. (2015). Limesurvey: an open source survey tool; Limesurvey project: Hamburg, Germany URL http://www.limesurvey.org.

44. Schwarzer, R., \& Jerusalem, M. (1995). Generalized self-efficacy scale. In J. Weinman, S. Wright, \& M. Johnston, Measures in health psychology: A user's portfolio. Causal and control beliefs (pp. 35-37). Windsor, UK: NFER-NELSON.

45. Sherry JL, Lucas K, Greenberg BS, Lachlan K. Video game uses and gratifications as predictors of use and game preference. Playing video games: Motives, responses, and consequences. 2006;24:213-24. 
46. Smyth JM. Beyond self-selection in video game play: an experimental examination of the consequences of massively multiplayer online role-playing game play. Cyberpsychol Behav. 2007;10(5):717-21.

47. Spencer, S. J., Josephs, R. A., \& Steele, C. M. (1993). Low self-esteem: the uphill struggle for self-integrity. In Baumister, R (Ed.), Self-Esteem (pp. 21-36). Springer US.

48. Stetina B, Kothgassner O, Lehenbauer M, Kryspin-Exner I. Beyond the fascination of online-games: Probing addictive behavior and depression in the world of online-gaming. Comput Hum Behav. 2011;27: 473-9.

49. Strahan R, Gerbasi KC. Short, homogeneous versions of the Marlow-Crowne social desirability scale. J Clin Psychol. 1972;28(2):191-3.

50. Thoits PA. Stressors and problem-solving: the individual as psychological activist. J Health Soc Behav. 1994;35(2):143-60.

51. Wang C, Khoo A, Liu W, Divaharan S. Passion and intrinsic motivation in digital gaming. CyberPsychol Behav. 2008;11:39-45.

52. Williams D, Yee N, Caplan S. Who plays, how much, and why? Debunking the stereotypical gamer profile, Journal of Computer-Mediated Communication. 2008;13:993-1018.

53. Williams D, Ducheneaut N, Xiong L, Zhang Y, Yee N, Nickell E. From tree house to barracks: the social life of guilds in world of Warcraft. Games and Culture. 2006;1:338-61.

54. Yee N. The demographics, Motivations and Derived Experiences of Users of Massively-Multiuser Online Graphical Environments. Teleoperators and Virtual Environments. 2006;15:309-29.

Publisher's Note Springer Nature remains neutral with regard to jurisdictional claims in published maps and institutional affiliations.

Dr Cian Goh Clin Psy D is now clinical psychologist at the National University Health System, Singapore.

Dr Christopher A Jones Consultant Clinical Neuropsychologist (University Hospital Birmingham, UK) and Director of Research for the Doctorate in Clinical Psychology, Centre for Applied Psychology, School of Psychology; University of Birmingham, UK.

Professor Alex Copello PhD is Professor of addiction research at the University of Birmingham, UK and Associate Director of Research for Birmingham and Solihull Mental Health Foundation NHS Trust. 